"Este documento é a versão do artigo submetido à publicação. Portanto, trata-se da versão não editada de um trabalho que, após revisão por pares, foi aceito para publicação no "Journal Agricultural and Food Chemistry". Copyright @American Chemical Society (ACS). Para acessar o trabalho final editado e publicado, consulte: https://pubs.acs.org/doi/abs/10.1021/acs.jafc.9b00806?mi=aayia761\&af=R\&AllField=n ano\&target=default\&targetTab=std\&

\title{
A mechanistic view of interactions of a nanoherbicide with target organism
}

Aline Bertolosi Bombo ${ }^{a, 1^{*}}$, alinebbombo@gmail.com

Anderson Espírito Santo Pereira ${ }^{b}$, espdna@gmail.com

Makeli Garibotti Lusac', makelilus@yahoo.com.br

Eliana Medeiros de Oliveirac ${ }^{c}$, eliana.medeiros@ufsc.br

Jhones Luis de Oliveira ${ }^{b}$, jholuisoliveira@hotmail.com

Estefânia Vangelie Ramos Campos ${ }^{b}$, estefaniavan@gmail.com

Marcelo Bispo de Jesus ${ }^{d}$, dejesus@unicamp.br

Halley Caixeta Oliveira ${ }^{e}$, halleycaixeta@gmail.com

Leonardo Fernandes Fraceto ${ }^{d}$, leonardo.fraceto@unesp.br

Juliana Lischka Sampaio Mayer ${ }^{a}$, mjimayer@yahoo.com.br

a Department of Plant Biology, Institute of Biology, P.O.Box 6109, University of Campinas - Unicamp, 13083-970, Campinas, SP, Brazil

b São Paulo State University - UNESP, Laboratory of Environmental Nanotechnology, Institute of Science and Technology, 18087-180, Sorocaba, SP, Brazil

C Santa Catarina State University - UFSC, Department of Botany, 88040-900, Florianópolis, SC, Brazil

d Department of Biochemistry and Tissue Biology, Nano-Cell Interactions Lab, Institute of Biology, P.O.Box: 6109, University of Campinas - UNICAMP, 13083970, Campinas, SP, Brazil. 
E Department of Animal and Plant Biology, State University of Londrina, PR 445, km 380, CEP 86047-970, Londrina, PR, Brazil

* Corresponding author: alinebbombo@gmail.com; phone +55 19 3526-4200; fax +55 19 3526-4201

1 Present address: São Paulo State University (UNESP), Institute of Biosciences, 13506-900, Rio Claro, SP, Brazil

\section{Abstract}

Atrazine is one of the most used herbicides and has been associated with persistent surface and groundwater contamination, and novel formulations derived from nanotechnology can be a potential solution. We used poly-epsilon caprolactone nano-encapsulation of atrazine (NC+ATZ) to develop a highly effective herbicidal formulation. Detailed structural study of interaction between the formulation and Brassica juncea plants was carried out with evaluation of the foliar uptake of nanoatrazine and structural alterations induced in the leaves. Following postemergent treatment, NC+ATZ adhered to the leaf and penetrated mesophyll tissue mainly through the hydathode regions. NC+ATZ was transported directly through the vascular tissue of the leaves and into the cells where it degraded the chloroplasts resulting in herbicidal activity. Nanocarrier systems, such as the one used in this study, have a great potential for agricultural applications in terms of maintenance of herbicidal activity at low concentrations and a substantial increase in the herbicidal efficacy.

Keywords: atrazine, confocal microscopy, leaf uptake, nanoherbicide, PCL nanocapsules. 


\section{Introduction}

In the last few decades, agriculture has used new substances, tools, and technologies, such as pesticides and biotechnology, to reduce pests and diseases to increase production and quality of agricultural produce. However, many of these technologies have also led to concerns over food safety and environmental impacts. Nanotechnology is an important innovation that can boost modern agriculture by protecting crops with a low environmental impact ${ }^{1-6}$. Nanotechnology offers a number of innovations to conventional systems, such as fertilizers and pesticides, pathogen detection ${ }^{6,7}$, and soil and water remediation ${ }^{8}$. Therefore, the industry has a keen interest in the potential applications of nanotechnology for improvements in agri-food production, processing, packaging and development of innovative products.

A major challenge for modern farming is to increase production while decreasing the resulting environmental impacts ${ }^{6,9,10}$. In this context, the use of nanoparticles as nanocarriers of bioactive substances, such as pesticides, can benefit both farmers and the environment. The encapsulation of bioactive substances in nanocarriers may increase their solubility, protect against degradation, and promote a sustained and gradual release of the substance. This could lead to a reduction in the use of chemical substances in the field due to increase in effectiveness against pests and diseases ${ }^{11-13}$ and thus reduce costs and environmental footprint of the chemicals ${ }^{9}$.

Several nanoparticle-based systems, using different polymers and pesticides, have been developed to improve crop quality through more effective pest control ${ }^{14}$. As example, Maruyama et al. ${ }^{15}$, developed a system based on chitosan nanoparticles loaded with the herbicides imazipic and imazapyr. According to Oliveira et al. ${ }^{16}$, the encapsulation of essential oils in zein nanoparticles has potential to increase insecticide and repellent activities. Pereira et al. ${ }^{17}$ showed the potential of chitosan nanoparticles for plant growth regulators for increase the 
development of plants. In this context, studies into nanocarrier applications in agriculture is a relatively new, and ongoing assessment is essential to ensure that these systems do not become a new source of contamination for food and the environment ${ }^{18,19}$.

In plants, the physicochemical characteristics of nanocarriers may affect biological activity, particularly through interactions between the environment and living organisms ${ }^{20}$. Nanoparticle size is one of the main factors that affect penetration and accumulation in plant cells, in addition to other aspects such as chemical composition, morphology, and coating ${ }^{9}$. Another factor is the surface charge on nanoparticles, known as the zeta potential, which affects interactions with different biological components such as proteins and carbohydrates, and consequently interferes with the absorption, transport, or bioaccumulation of nanoparticles in plants ${ }^{20-23}$.

The polymer poly- $\varepsilon$-caprolactone $(\mathrm{PCL})$ is obtained by the polymerization of the cyclic monomer $\varepsilon$-caprolactone. It is a semicrystalline polymer that is soluble in organic solvents and is biodegradable and biocompatible. It is therefore ideal for use in sustained release systems in agricultural applications ${ }^{24}$.

PCL nanocapsules containing the herbicide atrazine have been developed to reduce the herbicide's side-effects while maintaining herbicidal activity. They can be prepared by different methodologies in the form of systems with physicochemical stability that promotes a sustained release of atrazine ${ }^{25,26}$. In a previous study, the encapsulation of atrazine in PCL nanocapsules was shown to potentiate atrazine's herbicidal activity ${ }^{27}$. Indeed, in contrast to a commercial atrazine formulation, this system maintained post-emergent control of weeds in Brassica juncea (L.) Czern. crop even at 10 -fold dilution ${ }^{27}$. In addition, atrazine-containing PCL nanocapsules showed no persistent toxic effects in the non-target crop of maize (Zea mays L.) ${ }^{28}$. These systems have also been shown to have lower toxicity of the herbicide in Allium cepa L. and human cells than its free (unencapsulated) form ${ }^{25,26}$. 
Whilst many studies have focused on the effects of nanoherbicides in target organisms, only a few have investigated the mechanism of action in plants. Indeed, studies that evaluate the uptake and structural effects of nanoherbicides in plants are of extreme importance, because they can support the design of new nanocarrier systems for desired applications. The present study evaluated morphoanatomical effects of PCL nanocapsules containing atrazine on mustard plants ( $B$. juncea) to understand the nanocapsule-plant interactions. We specifically investigated phytotoxicity and nanoparticle uptake. To the best of our knowledge, this is the first study that has investigated such interactions between a polymeric nanocapsule containing an herbicide and a target species.

\section{Material and Methods}

\section{Materials}

The PCL polymer (molecular weight 80,000 Dalton) and atrazine were purchased from Sigma-Aldrich. The commercial formulation used as a reference was Gesaprim 500 CG obtained from Syngenta. B. juncea seeds were purchased from Topseed Garden-Agristar (Santo Antonio de Posse, Brazil).

\section{PCL nanocapsules}

PCL nanocapsules containing atrazine were prepared by the interfacial deposition of preformed polymer ${ }^{26}$. The organic phase was composed of $100 \mathrm{mg}$ of PCL, $30 \mathrm{~mL}$ of organic solvent (acetone), $200 \mathrm{mg}$ of Myritol $^{\circledR} 318$ oil, $40 \mathrm{mg}$ of surfactant (sorbitan monostearate-SPAN ${ }^{\circledR} 60$ ), and $10 \mathrm{mg}$ of atrazine. The aqueous phase was composed of $30 \mathrm{~mL}$ of water containing $60 \mathrm{mg}$ of surfactant (Polysorbate 80-Tween $\left.{ }^{\circledR} 80\right)$. After complete dissolution of the components for both phases, the organic phase was slowly poured into the aqueous phase (maintained under constant stirring) with a funnel, and the resulting mixture was stirred for $10 \mathrm{~min}$. The total volume was evaporated to $10 \mathrm{~mL}$. Labeled nanoparticles were prepared by 
adding the fluorophore 1,2-dipalmitoyl-sn-glycero-3-phosphoethanolamine- N(Lissamine $^{\mathrm{TM}}$ rhodamine B sulfonyl chloride) $(0.1 \%$ of the PCL mass) to the organic phase.

\section{Dynamic light scattering (DLS) and zeta potential}

The size distribution and polydispersity index (PDI) of the nanoparticles were determined by the DLS technique, with the scattered light detected at an angle of $90^{\circ}$ using a Zetasizer Nano ZS90 instrument (Malvern Instruments, UK). The zeta potential was evaluated using the same instrument by electrophoresis. The samples were analyzed in triplicate at $25^{\circ} \mathrm{C}$.

\section{Nanoparticle tracking analysis (NTA)}

After preparation, the nanocapsules were characterized in relation to their size and concentration by NTA using a Nanosight Model LM 10 (Malvern Instruments). The formulations were diluted 5,000-fold and the samples were evaluated in five replicates, counting 100 nanoparticles per sample. Analyses were performed at $25^{\circ} \mathrm{C}$.

\section{Plant material and growth conditions}

B. juncea was used as the model target species. Seed germination was performed in plastic pots filled with a mixture of substrate for seedlings $\left(\right.$ Genebom $\left.^{\circledR}\right)$ and vermiculite (Isoplus $\left.{ }^{\circledR}\right)(2: 1, w / w)$. After seedling emergence, four individual plants were grown in each pot until they had a pair of fully expanded leaves (about one month later). Throughout cultivation, the plants were kept in a growth chamber at $25^{\circ} \mathrm{C}, 10 \mathrm{~h}$ photoperiod, with daily manual irrigation. The experiments were conducted from April to June (fall).

\section{Herbicidal activity assays and symptom evaluation}

Thirty-day-old mustard plants were treated with the following formulations: distilled water (control), herbicide-free nanocapsules (control nanoparticles, NC), commercially formulated atrazine at $1 \mathrm{mg} \mathrm{mL}^{-1}$ (ATZ), and nanocapsules containing 
10-fold diluted atrazine at $0.1 \mathrm{mg} \mathrm{mL} \mathrm{mL}^{-1}(\mathrm{NC}+\mathrm{ATZ})$. The standard concentration of atrazine in the nanoformulation was $1 \mathrm{mg} \mathrm{mL}^{-1}$; however, we decided to use a 10 fold-diluted NC+ATZ solution because Oliveira et al. ${ }^{28}$ showed that the formulation maintained efficacy against the target at this concentration. For each formulation, at least five pots were sprayed with $5 \mathrm{~mL}$ of the test sample, resulting in an application of atrazine that is recommended by the manufacturer $(2,000 \mathrm{~g}$ atrazine per hectare) ${ }^{27}$. Herbicide-free nanoparticles added by Lissamine ${ }^{T m}$ rhodamine $B$ sulfonyl chloride were applied in the same way for plants used in the confocal analysis, as described below. All of the treatments were applied in the morning (before $9 \mathrm{am}$ ).

Symptoms of effects in the leaves were recorded at 3 and 7 days after treatment. Photographic images were taken under the same conditions, and the background and color were adjusted using CorelDRAW X6 software.

\section{Morphoanatomical characterization}

Confocal laser scanning microscopy. Leaf samples measuring $3 \times 2 \mathrm{~mm}$ were fixed in $4 \%$ paraformaldehyde in phosphate buffer for $4 \mathrm{~h}$ at $4{ }^{\circ} \mathrm{C}$, washed with buffer and plated on round glass slides using an aqueous mounting medium (Dako Faramount S3025), and stored at $4{ }^{\circ} \mathrm{C}$ until analysis. Samples were analyzed with a Zeiss LSM 510 confocal microscope (Carl Zeiss, Jena, Germany) using an Argon 488-nm laser, "Plan-Neofluar" 20, 40, and 63x 1.3 oil lens, and LSM 510 version 2.02 software. Images were taken at a resolution of $1024 \times 1024$ pixels.

Light microscopy. One-millimeter-long leaf samples were selected from each treatment and fixed in $3 \%$ glutaraldehyde and $0.2 \mathrm{~mol} \mathrm{~L}^{-1}$ sodium cacodylate buffer $(\mathrm{pH} 7.25,24 \mathrm{~h})$, post-fixed in $1 \%$ osmium tetroxide in $0.1 \mathrm{~mol} \mathrm{~L}^{-1}$ phosphate buffer $(\mathrm{pH} 7.2)$, and processed using standard methods ${ }^{29}$. Dehydration was performed through a graded alcohol series with subsequent embedding in hydrophilic acrylic resin (LR White Hard Grade; Fluka). Samples were then embedded in the same resin and polymerized in an oven at $60{ }^{\circ} \mathrm{C}$ for $12-24 \mathrm{~h}$. Semithin sections were 
prepared using a Leica UC7 ultramicrotome with a glass blade. The sections were stained using $0.05 \%$ toluidine blue $\mathrm{O}$ in citrate-phosphate buffer, $\mathrm{pH} 4.5^{30}$, and permanently mounted on slides with Entellan ${ }^{\circledR}$ synthetic resin (Merck, Darmstadt, Germany). Images were captured using an Olympus DP71 digital camera coupled to an Olympus BX51 microscope.

Scanning and transmission electron microscopy (SEM and TEM). For SEM and TEM, 1-mm-long samples were selected near the leaf edge in the hydathode regions of the leaf blade. For SEM, samples were fixed in Karnovsky solution ${ }^{31}$, dehydrated in an acetone series up to absolute acetone, dried using the critical point method with $\mathrm{CO}_{2}{ }^{32}$, mounted on aluminum stubs, and coated with a layer of $30-40 \mathrm{~nm}$ gold using a Balzers SCD 050 sputter-coater. Observations and photomicrographs were obtained using a JEOL JSM 5800LV at $20 \mathrm{kV}$ with SemAfore 5.21 software, and scale bars were directly printed onto the electron micrographs generated.

For TEM, samples were fixed and prepared as described for light microscopy. Ultrathin sections were prepared using a Leica UC7 ultramicrotome with a diamond blade (Diatome) at $45^{\circ}$ to a 60 -nm thickness and were placed on 100 -mesh copper grids. Counterstaining was performed using an aqueous solution of $5 \%$ uranyl acetate and $1 \%$ lead citrate for 10 min each for contrast ${ }^{33}$. TEM was performed using a JEOL JEM 1011 at $80 \mathrm{kV}$.

\section{Results and Discussion}

\section{Nanocapsule characterization}

The use of PCL has several advantages over other polymers, such as its biodegradability and biocompatibility. It is ideal for use in sustained release systems for agricultural applications ${ }^{24}$, and also cheap and easy to manufacture ${ }^{34}$. Moreover, ATZ-loaded PCL nanocapsules are a reservoir system, which is composed 
by an oil nucleus covered bythe polymeric core. ATZ interacts mainly with the oily phase due to its hydrophobicity; however, due to hydrophobic characteristics of PCL and due to the presence of the surfactant in the nanoparticle surface, ATZ molecules can be distributed from the inner core to the surface of the nanoparticles.

Characterization of nanocapsules was conducted using two different methods, DLS and NTA. Both techniques define size, but DLS also show the PDI and zeta potential by electrophoresis, and NTA provide an estimate of nanoparticle

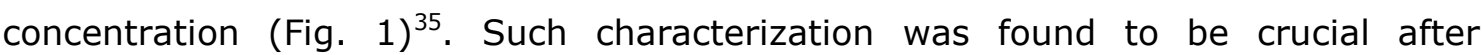
nanocapsule synthesis by Grillo et. al. ${ }^{26}$, particularly in relation to size, PDI, zeta potential, morphology, and release profile of bioactive substances.

The DLS analysis (Fig. 1A, C) revealed that the particle size of NC+ATZ was $256 \pm 2.3 \mathrm{~nm}$, and when labeled, the size increased to $345 \pm 3.1 \mathrm{~nm}$. The NTA analysis (Fig. 1B, D) revealed that regardless of whether the NC+ATZ nanoparticles were labeled or not, they had the same size $(\sim 258 \mathrm{~nm})$. The NTA also showed that nanoparticle concentration was approximately $9.20 \times 10^{12}$ nanoparticles/mL for $\mathrm{NC}+\mathrm{ATZ}$ and $9.36 \times 10^{12}$ nanoparticles $/ \mathrm{mL}$ for the labeled nanoparticles. These results show that there was no major change in nanoparticle concentration due to labeling. The DLS analysis showed that NC+ATZ had a PDI of $0.09 \pm 0.02$, and when labeled, a PDI of $0.23 \pm 0.015$, which showed an increase in a polydispersity of the nanoparticles due to labeling. Despite the increase of PDI, the NTA showed that the largest fraction of nanoparticles had a size of $258 \mathrm{~nm}$.

The zeta potential was determined by electrophoresis and was approximately $-32 \mathrm{mV}$ for both nanoparticles (labeled and unlabeled). The nanoparticle control (NC) (without the active) had the same size, PDI, zeta potential, and concentration of nanoparticles as those containing atrazine, or were labeled (Fig 1). The nanoparticles had the characteristics as described previously by Grillo et al. ${ }^{26}$, and labeled nanoparticles had the same characteristics as described 
by Jacques et al. ${ }^{36}$. According Grillo et al. ${ }^{26}$, the nanoparticles have a spherical shape, with an encapsulation efficiency about $86 \%$ and a loading capacity of $2 \%$.

\section{Macroscopic effect evaluation}

To understand the relationship between exposure and effect it is important to study nanoparticle uptake. We investigated PCL nanocapsule uptake in mustard leaves using several techniques. These included macroscopic and microscopic evaluations, confocal laser scanning microscopy, SEM, and TEM, to gain a broad understanding of the interactions.

Untreated, fully expanded mustard leaves exhibited a light-green coloration, with a central vein and ornamentation on the edge (Fig. 2A, water). The first macroscopic signs of atrazine toxicity were observed 3 days after the treatments, both in leaves sprayed with commercially formulated atrazine and with NC+ATZ (Fig. 2A). In both treatments, the leaves exhibited a yellowish coloration, particularly near the veins and the edge of the leaf. After 7 days (Fig. 2B), NC (control) maintained normal development and appearance, suggesting that there were no side-effects of the nanocapsules. In contrast, in samples treated with NC+ATZ or commercial solution alone (ATZ), most leaves had wilted and had chlorotic and necrotic areas. The symptoms were most evident from the border to the middle of the lamina, and yellowish areas near the veins were visible at this stage in both treatments. These symptoms are known to be elicited by atrazine, which causes interveinal and marginal chlorosis and ultimately death ${ }^{37}$, and are consistent with those observed by Oliveira et al. ${ }^{27}$, who demonstrated that encapsulation maintained atrazine's mechanism of action against mustard plants even at a 10 -fold lower application.

\section{B. juncea leaf characterization}


Healthy, untreated $B$. juncea leaves were anatomically characterized to investigate the possible effects of nanoparticles in the tissues. Transversal sections revealed hydathodes on the leaf margin (Fig. 3A-D). These are water pores (modified stomata; Fig. 3C, D, arrows), layers of thin-walled epithem cells below the epidermis (Fig. 3D), and terminal tracheids in the vascular bundle. In the middle of the leaf blade (Fig. 3E) the epidermis was uniseriate, with thick outer periclinal walls and stomata in both leaf faces. There was also dorsiventral heterogeneous mesophyll, and small lateral veins composed of vascular bundles immersed between palisade and spongy parenchyma. Chloroplasts were welldeveloped and could be observed in the chlorophyllous parenchyma, with starch grains in most of them (Fig. 3E).

\section{Nanoparticle penetration}

Although several studies have investigated the macroscopic effects of nanocapsules and nanoherbicides in target organisms, few have focused on their uptake and mechanism of action. Visualization of nanoparticle uptake into the leaves was possible using nanoparticles labeled with a fluorescent dye (Lissamine ${ }^{\mathrm{Tm}}$ rhodamine B sulfonyl chloride) followed by confocal microscopy. As a result, a green fluorescent signal of the dye indicated the position of the nanoparticles in the NC and NC+ATZ treatments (Fig. 4, arrows). In the first $24 \mathrm{~h}$, nanoparticles were deposited on the leaf surface, there was no nanoparticle penetration (Fig. 4A, C, E) and no fluorescent signal was observed inside the leaf in the mesophyll (Fig. 4B, D, F).

After $48 \mathrm{~h}$ of incubation (Fig. 4G, H), it was possible to observe the particles in the vessel elements (Fig. 4H), and after $96 \mathrm{~h}$ of incubation (Fig. 4I, L), particles were observed in the stomata (Fig. 4I), interspersed among mesophyll cells (Fig. 4J), and in vessel elements (Fig. 4K, L), showing that the particles penetrate stomata, particularly those in hydathode regions. 
In the NC treatment after $168 \mathrm{~h}$ of incubation (Fig. 4M-P), the green fluorescent signal of the nanoparticles was still detected inside vessel elements and mesophyll cells with intact tissue (Fig. 4M, N). NC+ATZ were found in similar regions; however, the leaf tissue was extensively damaged, indicating atrazine activity (Fig. 40, P).

Hydathode regions have a high concentration of modified stomata (water pores), which are directly connected to the vascular system through terminal tracheids in the vascular bundle ${ }^{38}$. They mediate water exudation, a process that generally occurs in conditions of high water uptake and limited transpiration, such as warm soils and high humidity ${ }^{39}$. However, foliar water uptake is also attributed to hydathodes ${ }^{40-43}$.

Hydathodes water pores can vary from a few microns up to several microns ${ }^{44}$, a size that could allow nanocarrier entry ${ }^{21}$. Moreover, in our experiment, the plants were kept well-hydrated, thus favoring stomatal aperture. Nanoencapsulated form of atrazine could also travel directly through the vascular system and spread rapidly throughout the whole plant, accelerating the activity of nanoencapsulated atrazine. Nguyen et al. ${ }^{21}$ reported that nanocarrier penetration in pepper leaves is rapid and can reach the deepest parts of the leaf blade just 60 min after application. In pepper leaves, as in mustard leaves, stomata are found on both leaf surfaces, which facilitates rapid penetration in these species, because stomata, and consequently hydathode regions, are ideal pathways for nanocarrier leaf penetration ${ }^{21}$.

Another factor is that the PCL nanoparticles used in our experiments had a negative zeta potential, and according to Nguyen et al. ${ }^{21}$, negatively-charge nanoparticles have a faster foliar penetration than those with positive zeta potential. Plant cell walls have a negative charge because of the large presence of polysaccharides rich in galacturonic or glucuronic acids units, such as pectin and glucuronoarabinoxylan ${ }^{45}$. Due to the electrostatic interaction, nanoparticles with 
positive charge accumulate and aggregate in the tissue surface. In contrast, negatively-charged nanoparticles usually show higher distribution inside the plants, given its poor interaction with cell wall. This behavior has been described for cerium oxide and gold nanoparticles ${ }^{45,46}$.

\section{Structural aspects}

Macroscopic symptoms of atrazine toxicity were observed after only 3 days in plants treated with atrazine. Anatomically, the symptoms of atrazine toxicity were already seen from the second day ( 48 h) after leaves were sprayed with commercially formulated atrazine and with NC+ATZ. Further structural insights were gained by SEM (Fig. 5A-I). After 48 h, epidermal cells (Fig. 5D, E), particularly on the adaxial surface near to the edge of the leaf blade and in the hydathode regions, exhibited less turgor in the NC+ATZ and ATZ treatments than after $24 \mathrm{~h}$ (Fig. 5A-C). From that timepoint onwards (Fig. 5F-I) the symptoms increased, and cell turgor continuously decreased, particularly in the last stage (168 h). Leaves subjected to water and NC treatments were unchanged (Figs. 2C, 5A, G).

Light microscopy (Fig. 6A-L) revealed that atrazine toxicity (Fig. 6I-L) symptoms were visible from $48 \mathrm{~h}$ when it was possible to observe the abnormal development of the chloroplasts followed by chlorophyllous parenchyma cell degradation when compared to the water control (Fig. 6A, B). In the water and NC treatments (Fig. 6C, D), no structural changes in the leaves were observed, while in the $\mathrm{NC}+\mathrm{ATZ}$ treatment (Fig. $6 \mathrm{E}-\mathrm{H}$ ), the changes were similar to those observed in the ATZ treatment, with plastid deterioration (Fig. 6H and inset). Cell degradation, as observed in the ATZ treatment, was not observed in the NC+ATZ treatment until after $168 \mathrm{~h}$; however, considering the macroscopic symptoms (Fig. 2) and further observations (data not shown), cell degradation must have occurred. 
In the control samples (Fig. 7A-D), the cells were intact, all of the organelles had developed normally, the cell walls and plasma membranes were intact (Fig. 7A), the mitochondria had well-developed cristae, and chloroplasts had a normal thylakoid organization (Fig. 7B, D) with a few plastoglobuli (Fig. 7C, D).

In the nanoparticle-containing treatments (Fig. 7E-R), $12 \mathrm{~h}$ after the $\mathrm{NC}+\mathrm{ATZ}$ treatment (Figure $7 \mathrm{~K}$ ) and from the 36 -h stage in the NC treatment (Fig. 7G, $H$ ), the presence of particles with the same size as the nanoparticles used for the treatments (Fig. 1) was observed inside NC+ATZ treatment, first cell damages were recorded at $36 \mathrm{~h}$, and at $48 \mathrm{~h}$ the chloroplasts (Fig. $7 \mathrm{~N}, 0$ ) had lost their characteristic shape, become unstructured, starch grains had disappeared from the system, a large number of supersized plastoglobuli had accumulated, and frets had been destroyed, resulting in granum arrangement disorganization. In the last stages (96 and $168 \mathrm{~h}$ ), the plastids had lost their structural organization (Fig. 7PR). These effects were also observed in the ATZ treatment (Fig. 7S-V). The only difference between the NC+ATZ and ATZ treatments was that in the latter the herbicidal effects were faster, with chloroplast structural disorganization occurring at $24 \mathrm{~h}$ (Fig. 7S) and complete cell damage at $168 \mathrm{~h}$ (Fig. 7V). Regardless of treatment (NC+ATZ or commercial ATZ), all of the cells were damaged, and the photosynthetic system was destroyed.

The primary effect of atrazine in the leaves is to inhibit photosystem II activity, which in a previous study was observed $24 \mathrm{~h}$ after treating mustard plants with ATZ or NC+ATZ ${ }^{28}$. A greater decrease in photosystem II activity occurred $48 \mathrm{~h}$ after treatment ${ }^{28}$, which coincided with nanocapsule penetration reaching the mesophyll cells. At this timepoint, the induction of oxidative stress by atrazine was detected ${ }^{28}$, which could have been related to the onset of anatomical symptoms such as cell turgor reduction, abnormal chloroplast development, and parenchyma cell degradation. As a consequence, macroscopic symptoms could be observed 72 days after treatment with both atrazine treatments (ATZ and NC+ATZ). 
Penetrating the leaf's barriers is a key point when considering a nanosystem. As we have demonstrated, nanoparticles penetrate the leaf through natural openings, i.e., water pores and stomata; however, translocation beyond the leaf is probably also mediated by apoplastic and symplastic pathways ${ }^{47,48}$, because we found nanoparticles inside cell protoplasts after only $36 \mathrm{~h}$ of incubation, and inside the chloroplasts after $48 \mathrm{~h}$ of incubation. The penetration mechanism seems to involve endocytosis ${ }^{49,50}$, in which nanoparticles pass through the cell wall and reach the cell membrane that invaginates, resulting in the internalization of the nanomaterial within a vesicle in the cytoplasm. These particles first appear near the cell wall and plasma membrane, followed by the vesicles. It is noteworthy that the PCL nanocarrier system does not generate phytotoxic effects, as the NC treatment did not cause any structural alterations, despite the presence of nanoparticles inside the cells, suggesting that they could be used for the delivery of different agents inside the leaf mesophyll, particularly targeting the chloroplasts.

Cell damage in the NC+ATZ and ATZ treatments involved chloroplast disorganization followed by supersized plastoglobuli accumulation, fret destruction, granum arrangement disorganization, and rapid starch grain consumption after photosynthesis blocking. All of these alterations are atrazine effects 51 , demonstrating that ATZ-loaded nanoparticles are effective at low herbicide dosages and toxic to target plant tissue.

In a previous study, Grillo et al. ${ }^{26}$ showed that PCL nanocapsules have a sustained release: $72 \%$ of ATZ was released after 5 days using a two-compartment model. Also, the release mechanism was based on non-Fickian process, indicating the ATZ release was controlled by the relaxation of the polymeric chains. Oliveira et al. ${ }^{52}$ demonstrated that atrazine encapsulation led to an increased inhibition of the photosystem II activity of mustard plants, indicating that ATZ reached its site of action. Here, we demonstrated that nanoparticles were absorbed through hydathode region and internalized by the cells. Taken together, these studies 
indicate that ATZ was released after nanoparticle uptake. However, further studies are necessary to elucidate the ATZ release from nanoparticles in plant tissues, using for example ${ }^{14} \mathrm{C}$-atrazine.

Controlled release is not the only objective of a nanocarrier system, as this system could also increase the accumulation of the active component at the intracellular level in target organelles. Therefore, nanocarriers can maintain the concentration of the active component at an optimal level for biological activity, and also reduce resistance ${ }^{53}$. The absorption mode, translocation, and cell uptake of PCL nanoparticles as revealed by the present study highlight the high efficiency of this system at low concentrations.

Nanocarrier systems for herbicides have great potential for agricultural applications, so understanding the underlying mechanisms of action of these materials is of great importance to ensure their safety, as well as for designing more efficient systems. In conclusion, we found that nanocapsules containing atrazine efficiently adhered to the leaf surface and penetrated into the mesophyll through stomata on the leaf edge. Consequently, the nanocapsules efficiently delivered atrazine to the site of action, and the herbicidal activity was remarkably strong even when diluted 10 -fold. This means that the nano-scale formulation of atrazine could enable a major reduction in the use of herbicides and consequently reduce the overall costs and negative impacts on the environment. The fact that PCL nanocapsules (without atrazine) were harmless in terms of phytotoxic effects and effects on the plant's structure shows that they provide a very useful means for delivery of active substances into the leaf mesophyll. Although more understanding of toxicological aspects towards non-target plant and animal species is required, our study provides a foundation for further research into efficient delivery of atrazine and other bioactive substances in their use in a safe and sustainable way.

\section{Abbreviations used}


ATZ Commercially formulated atrazine at $1 \mathrm{mg} \cdot \mathrm{mL}^{-1}$

NC Herbicide-free nanocapsules (control nanoparticles)

NC+ATZ Nanocapsules containing atrazine ten-fold diluted at $0.1 \mathrm{mg} \cdot \mathrm{mL}^{-1}$

PCL Poly- $\varepsilon$-caprolactone

\section{Acknowledgments}

We thank São Paulo Research Foundation (FAPESP) Thematic Project 2017/21004-5 and the Coordination for the Improvement of Higher Education Personnel (CAPES) funding and support. We also thank the access to equipment and assistance provided by the Electron Microscope Laboratory (LME), and by the National Institute of Science and Technology on Photonics Applied to Cell Biology (INFABIC) at the State University of Campinas; INFABIC is co-funded by São Paulo Research Foundation (FAPESP) (08/57906-3) and Conselho Nacional de Desenvolvimento Cientifico e Tecnológico (CNPq) (573913/2008-0). We would like also to thank Qsaim Chaudhry for a friendly review. 


\section{References}

(1) Fraceto, L. F.; Grillo, R.; de Medeiros, G. A.; Scognamiglio, V.; Rea, G.; Bartolucci, C. Nanotechnology in Agriculture: Which Innovation Potential Does It Have? Front. Environ. Sci. 2016, 4 (March), 1-5. https://doi.org/10.3389/fenvs.2016.00020.

(2) Yusoff, S. N. M.; Kamari, A.; Aljafree, N. F. A. A Review of Materials Used as Carrier Agents in Pesticide Formulations. Int. J. Environ. Sci. Technol. 2016, 13 (12), 2977-2994. https://doi.org/10.1007/s13762-016-1096-y.

(3) Nuruzzaman, M.; Rahman, M. M.; Liu, Y.; Naidu, R. Nanoencapsulation, Nano-Guard for Pesticides: A New Window for Safe Application. J. Agric. Food Chem. 2016, 64 (7), 1447-1483. https://doi.org/10.1021/acs.jafc.5b05214.

(4) Parisi, C.; Vigani, M.; Rodríguez-Cerezo, E. Agricultural Nanotechnologies: What Are the Current Possibilities? Nano Today 2015, 10 (2), 124-127. https://doi.org/10.1016/j.nantod.2014.09.009.

(5) Kookana, R. S.; Boxall, A. B. A.; Reeves, P. T.; Ashauer, R.; Beulke, S.; Chaudhry, Q.; Cornelis, G.; Fernandes, T. F.; Gan, J.; Kah, M.; et al. Nanopesticides: Guiding Principles for Regulatory Evaluation of Environmental Risks. J. Agric. Food Chem. 2014, 62 (19), 4227-4240. https://doi.org/10.1021/jf500232f.

(6) Kah, M.; Singh Kookana, R.; Gogos, A.; Bucheli, T. A Critical Evaluation of Nanopesticides and Nanofertilizers against Their Conventional Analogues. Nat. Nanotechnol. 2018, 1. https://doi.org/10.1038/s41565-018-0131-1.

(7) Antonacci, A.; Arduini, F.; Moscone, D.; Palleschi, G.; Scognamiglio, V. Nanostructured (Bio)Sensors for Smart Agriculture. TrAC Trends Anal. Chem. 2018, 98, 95-103. https://doi.org/10.1016/J.TRAC.2017.10.022.

(8) Rawtani, D.; Khatri, N.; Tyagi, S.; Pandey, G. Nanotechnology-Based Recent Approaches for Sensing and Remediation of Pesticides. J. Environ. Manage. 
2018, 206, 749-762. https://doi.org/10.1016/J.JENVMAN.2017.11.037.

(9) Pérez-de-Luque, A. Interaction of Nanomaterials with Plants: What Do We Need for Real Applications in Agriculture? Front. Environ. Sci. 2017, 5 (April), 1-7. https://doi.org/10.3389/fenvs.2017.00012.

(10) Fraceto, L. F.; de Lima, R.; Oliveira, H. C.; Ávila, D. S.; Chen, B. Future Trends in Nanotechnology Aiming Environmental Applications. Energy, Ecol. Environ. 2018, 3 (2), 69-71. https://doi.org/10.1007/s40974-018-0087-x.

(11) Wang, P.; Lombi, E.; Zhao, F. J.; Kopittke, P. M. Nanotechnology: A New Opportunity in Plant Sciences. Trends Plant Sci. 2016, 21 (8), 699-712. https://doi.org/10.1016/j.tplants.2016.04.005.

(12) Campos, E. V. R.; de Oliveira, J. L.; Fraceto, L. F. Applications of Controlled Release Systems for Fungicides, Herbicides, Acaricides, Nutrients, and Plant Growth Hormones: A Review. Adv. Sci. Eng. Med. 2014, 6 (4), 373-387. https://doi.org/10.1166/asem.2014.1538.

(13) Khot, L. R.; Sankaran, S.; Maja, J. M.; Ehsani, R.; Schuster, E. W. Applications of Nanomaterials in Agricultural Production and Crop Protection: A Review. Crop Prot. 2012, 35, 64-70. https://doi.org/10.1016/j.cropro.2012.01.007.

(14) Pascoli, M.; Lopes-Oliveira, P. J.; Fraceto, L. F.; Seabra, A. B.; Oliveira, H. C. State of the Art of Polymeric Nanoparticles as Carrier Systems with Agricultural Applications: A Minireview. Energy, Ecol. Environ. 2018, 3 (3), 137-148. https://doi.org/10.1007/s40974-018-0090-2.

(15) Maruyama, C. R.; Guilger, M.; Pascoli, M.; Bileshy-José, N.; Abhilash, P. C.; Fraceto, L. F.; De Lima, R. Nanoparticles Based on Chitosan as Carriers for the Combined Herbicides Imazapic and Imazapyr. Sci. Rep. 2016, 6 (January). https://doi.org/10.1038/srep19768.

(16) Oliveira, J. L.; Campos, E. V. R.; Bakshi, M.; Abhilash, P. C.; Fraceto, L. F. 
Application of Nanotechnology for the Encapsulation of Botanical Insecticides for Sustainable Agriculture: Prospects and Promises. Biotechnol. Adv. 2014, 32 (8), 1550-1561. https://doi.org/10.1016/j.biotechadv.2014.10.010.

(17) Pereira, A. E. S.; Silva, P. M.; Oliveira, J. L.; Oliveira, H. C.; Fraceto, L. F. Chitosan Nanoparticles as Carrier Systems for the Plant Growth Hormone Gibberellic Acid. Colloids Surfaces B Biointerfaces 2017, 150, 141-152. https://doi.org/10.1016/j.colsurfb.2016.11.027.

(18) Iannone, M. F.; Groppa, M. D.; de Sousa, M. E.; Fernández van Raap, M. B.; Benavides, M. P. Impact of Magnetite Iron Oxide Nanoparticles on Wheat (Triticum Aestivum L.) Development: Evaluation of Oxidative Damage. Environ. Exp. Bot. 2016, 131, 77-88. https://doi.org/10.1016/j.envexpbot.2016.07.004.

(19) Hossain, Z.; Mustafa, G.; Komatsu, S. Plant Responses to Nanoparticle Stress. Int. J. Mol. Sci. 2015, 16 (11), 26644-26653. https://doi.org/10.3390/ijms161125980.

(20) Tripathi, D. K.; Shweta; Singh, S.; Singh, S.; Pandey, R.; Singh, V. P.; Sharma, N. C.; Prasad, S. M.; Dubey, N. K.; Chauhan, D. K. An Overview on Manufactured Nanoparticles in Plants: Uptake, Translocation, Accumulation and Phytotoxicity. Plant Physiol. Biochem. 2017, 110, 2-12. https://doi.org/10.1016/j.plaphy.2016.07.030.

(21) Nguyen, M. H.; Lee, J. S.; Hwang, I. C.; Park, H. J. Evaluation of Penetration of Nanocarriers into Red Pepper Leaf Using Confocal Laser Scanning Microscopy. Crop Prot. 2014, 66, 61-66. https://doi.org/10.1016/j.cropro.2014.08.016.

(22) Nguyen, M. H.; Nguyen, T. H. N.; Hwang, I. C.; Bui, C. B.; Park, H. J. Effects of the Physical State of Nanocarriers on Their Penetration into the Root and Upward Transportation to the Stem of Soybean Plants Using Confocal Laser 
Scanning Microscopy. Crop Prot. 2016, 87 (May), 25-30. https://doi.org/10.1016/j.cropro.2016.04.012.

(23) Prasad, A.; Astete, C. E.; Bodoki, A. E.; Windham, M.; Bodoki, E.; Sabliov, C. M. Zein Nanoparticles Uptake and Translocation in Hydroponically Grown Sugar Cane Plants. J. Agric. Food Chem. 2017, acs.jafc.7b02487. https://doi.org/10.1021/acs.jafc.7b02487.

(24) dos Santos, P. P.; Flôres, S. H.; de Oliveira Rios, A.; Chisté, R. C. Biodegradable Polymers as Wall Materials to the Synthesis of Bioactive Compound Nanocapsules. Trends Food Sci. Technol. 2016, 53, 23-33. https://doi.org/10.1016/J.TIFS.2016.05.005.

(25) Pereira, A. E. S.; Grillo, R.; Mello, N. F. S.; Rosa, A. H.; Fraceto, L. F. Application of Poly(Epsilon-Caprolactone) Nanoparticles Containing Atrazine Herbicide as an Alternative Technique to Control Weeds and Reduce Damage to the Environment. J. Hazard. Mater. 2014, 268, 207-215. https://doi.org/10.1016/j.jhazmat.2014.01.025.

(26) Grillo, R.; dos Santos, N. Z. P.; Maruyama, C. R.; Rosa, A. H.; de Lima, R.; Fraceto, L. F. Poly( $\varepsilon$-Caprolactone)Nanocapsules as Carrier Systems for Herbicides: Physico-Chemical Characterization and Genotoxicity Evaluation. J. Hazard. Mater. 2012, 231-232, 1-9. https://doi.org/10.1016/j.jhazmat.2012.06.019.

(27) Oliveira, H. C.; Stolf-Moreira, R.; Martinez, C. B. R.; Grillo, R.; De Jesus, M. B.; Fraceto, L. F. Nanoencapsulation Enhances the Post-Emergence Herbicidal Activity of Atrazine against Mustard Plants. PLoS One 2015, 10 (7), 1-12. https://doi.org/10.1371/journal.pone.0132971.

(28) Oliveira, H. C.; Stolf-Moreira, R.; Martinez, C. B. R.; Sousa, G. F. M.; Grillo, R.; de Jesus, M. B.; Fraceto, L. F. Evaluation of the Side Effects of Poly(Epsilon-Caprolactone) Nanocapsules Containing Atrazine toward Maize 
Plants. Front. Chem. 2015, 61. https://doi.org/10.3389/fchem.2015.00061.

(29) Roland, A. M. General Preparations and Staining of Thin Sections. In Electron microscopy and cytochemistry of plant cells; Hall, J. L., Ed.; Elsevier: New York, 1978; pp 1-62.

(30) Sakai, W. Simple Method for Differential Staining of Paraffin Embedded Plant Material Using Toluidine Blue. Stain technology. 1973, pp 247-249.

(31) Karnovsky, M. J. A Formaldehyde-Glutaraldehyde Fixative of High Osmolality for Use in Electron Microscopy. Cell Biol. Source J. Cell Biol. 1965, 27 (2), 1149.

(32) Horridge, G. A.; Tamm, S. L. Critical Point Drying for Scanning Electron Microscopic Sthdy of Ciliary Motion. Science 1969, 163 (3869), 817-818. https://doi.org/10.1126/science.163.3869.817.

(33) Reynolds, E. S. The Use of Lead Citrate at High PH as an Electron-Opaque Stain in Electron Microscopy. J. Cell Biol. 1963, 17, 208-212.

(34) Dash, T. K.; Konkimalla, V. B. Poly-€-Caprolactone Based Formulations for Drug Delivery and Tissue Engineering: A Review. J. Control. Release 2012, 158 (1), 15-33. https://doi.org/10.1016/J.JCONREL.2011.09.064.

(35) Filipe, V.; Hawe, A.; Jiskoot, W. Critical Evaluation of Nanoparticle Tracking Analysis (NTA) by NanoSight for the Measurement of Nanoparticles and Protein Aggregates. Pharm. Res. 2010, 27 (5), 796-810. https://doi.org/10.1007/s11095-010-0073-2.

(36) Jacques, M. T.; Oliveira, J. L.; Campos, E. V. R.; Fraceto, L. F.; Ávila, D. S. Safety Assessment of Nanopesticides Using the Roundworm Caenorhabditis Elegans. Ecotoxicol. Environ. Saf. 2017, 139, 245-253. https://doi.org/10.1016/j.ecoenv.2017.01.045.

(37) Ashton, F. M.; Gifford, Jr., E. M.; Bisalputra, T. Structural Changes in 
Phaseolus Vulgaris Induced by Atrazine I . Histological Changes. Bot. Gaz. 1963, $124(5), 329-335$.

(38) Fahn, A. Secretory Tissues in Vascular Plants. New Phytol. 1988, 108 (3), 229-257. https://doi.org/10.1111/j.1469-8137.1988.tb04159.x.

(39) Lersten, N. R.; Curtis, J. D. Laminar Hydathodes in Urticaceae: Survey of Tribes and Anatomical Observations on Pilea Pumila and Urtica Dioica. Plant Systematics and Evolution. Springer 1991, pp 179-203. https://doi.org/10.2307/23674658.

(40) Drennan, P. M.; Goldsworthy, D.; Buswell, A. Marginal and Laminar Hydathode-like Structures in the Leaves of the Desiccation-Tolerant Angiosperm Myrothamnus Flabellifolius Welw. Flora - Morphol. Distrib. Funct. Ecol. Plants 2009, 204 (3), 210-219. https://doi.org/10.1016/J.FLORA.2008.01.013.

(41) Martin, C. E.; von Willert, and D. J. Leaf Epidermal Hydathodes and the Ecophysiological Consequences of Foliar Water Uptake in Species of Crassula from the Namib Desert in Southern Africa. Plant Biol. 2000, 2 (2), 229-242. https://doi.org/10.1055/s-2000-9163.

(42) Willert, D. J. von; Eller, B. M.; Werger, M. J. A.; Brinckmann, E.; Ihlenfeldt, H.-D. Life Strategies of Succulents in Deserts, with Special Reference to the Namib Desert; University of Chicago Press, 1992. https://doi.org/10.1086/418213.

(43) Rundel, P. W. Water Uptake by Organs Other Than Roots. In Physiological Plant Ecology II; Springer Berlin Heidelberg: Berlin, Heidelberg, 1982; pp 111-134. https://doi.org/10.1007/978-3-642-68150-9_5.

(44) Wang, Y.; Noguchi, K.; Ono, N.; Inoue, S. -i.; Terashima, I.; Kinoshita, T. Overexpression of Plasma Membrane H+-ATPase in Guard Cells Promotes Light-Induced Stomatal Opening and Enhances Plant Growth. Proc. Natl. 
Acad.

Sci.

2014,

111

(1)，

$533-538$.

https://doi.org/10.1073/pnas.1305438111.

(45) Zhu, Z.-J.; Wang, H.; Yan, B.; Zheng, H.; Jiang, Y.; Miranda, O. R.; Rotello, V. M.; Xing, B.; Vachet, R. W. Effect of Surface Charge on the Uptake and Distribution of Gold Nanoparticles in Four Plant Species. Environ. Sci. Technol. 2012, 46 (22), 12391-12398. https://doi.org/10.1021/es301977w.

(46) Barrios, A. C.; Rico, C. M.; Trujillo-Reyes, J.; Medina-Velo, I. A.; PeraltaVidea, J. R.; Gardea-Torresdey, J. L. Effects of Uncoated and Citric Acid Coated Cerium Oxide Nanoparticles, Bulk Cerium Oxide, Cerium Acetate, and Citric Acid on Tomato Plants. Sci. Total Environ. 2016, 563-564, 956-964. https://doi.org/10.1016/j.scitotenv.2015.11.143.

(47) Karny, A.; Zinger, A.; Kajal, A.; Shainsky-Roitman, J.; Schroeder, A. Therapeutic Nanoparticles Penetrate Leaves and Deliver Nutrients to Agricultural Crops. Sci. Rep. 2018, 8 (1), 7589. https://doi.org/10.1038/s41598-018-25197-y.

(48) Schwab, F.; Zhai, G.; Kern, M.; Turner, A.; Schnoor, J. L.; Wiesner, M. R. Barriers, Pathways and Processes for Uptake, Translocation and Accumulation of Nanomaterials in Plants - Critical Review. Nanotoxicology 2016, 10 (3), 257-278. https://doi.org/10.3109/17435390.2015.1048326.

(49) Jesus, M. B. De; Kapila, Y. L. Nanotoxicology. 2014, 201-227. https://doi.org/10.1007/978-1-4614-8993-1.

(50) Doherty, G. J.; McMahon, H. T. Mechanisms of Endocytosis. Annu. Rev. $\begin{array}{llll}\text { Biochem. } & \text { 2009, (1), 857-902. }\end{array}$ https://doi.org/10.1146/annurev.biochem.78.081307.110540.

(51) Ashton, F. M.; Gifford, Jr., E. M.; Bisalputra, T. Structural Changes in Phaseolus Vulgaris Induced by Atrazine II. Effects on Fine Structure of $\begin{array}{llllll}\text { Chloroplasts. } & \text { Bot. } & \text { Gaz. } & \text { 1963, } & 124 & \text { (5), } 336 .\end{array}$ 
https://doi.org/10.1086/336215.

(52) Oliveira, H. C.; Stolf-Moreira, R.; Martinez, C. B. R.; Sousa, G. F. M.; Grillo, R.; de Jesus, M. B.; Fraceto, L. F. Evaluation of the Side Effects of Poly(Epsilon-Caprolactone) Nanocapsules Containing Atrazine toward Maize Plants. Front. Chem. 3 (October), 1-9. https://doi.org/10.3389/fchem.2015.00061.

(53) Shi, J.; Liu, W.; Fu, Y.; Yin, N.; Zhang, H.; Chang, J.; Zhang, Z. "USDetonated Nano Bombs" Facilitate Targeting Treatment of Resistant Breast Cancer. J. Control. Release 2018, 274, 9-23. https://doi.org/10.1016/j.jconrel.2018.01.030. 
Fig. 1. Nanoparticle characterization by dynamic light scattering (DLS) and nanoparticle tracking analysis (NTA). a) nanocapsule (NC) + atrazine (ATZ) and labeled NC + atrazine by DLS; b) NC + ATZ by NTA; c) Labeled NC + ATZ by DLS; and d) labeled NC + ATZ and labeled NC + atrazine by NTA. For DLS, the samples were analyzed in triplicate. For NTA, the samples were evaluated in five replicates, counting 100 nanoparticles per sample. Analyses were performed at $25^{\circ} \mathrm{C}$.

Fig. 2. Macroscopic symptom evolution in Brassica juncea leaves. Symptoms were recorded $3(A)$ and 7 (B) days after the plants were sprayed with water, unloaded nanocapsules (NC), nanocapsules containing atrazine at $0.1 \mathrm{mg} \mathrm{mL}^{-1}$ (NC + ATZ), or commercial atrazine at $1 \mathrm{mg} \mathrm{mL}^{-1}$ (ATZ). Scale bars $=2 \mathrm{~cm}$.

Fig. 3. Microscopic characterization of a healthy Brassica juncea leaf, showing the hydathode (1) and mesophyll (2) regions. Photograph (A), Scanning electron micrographs (B-C) and optical micrographs (D-E) of hydathodes on the leaf edge. Arrows in B indicate hydathodes. C. Detail of the B inset, arrows indicate water pores. D. Longitudinal section of a hydathode on the leaf edge, showing its anatomical structure. E. Transverse section of the middle region of the leaf blade (2), arrows indicate chloroplasts in the chlorophyll parenchyma. Ep = epithem, Epd $=$ epidermis, $\mathrm{Pp}=$ palisade parenchyma, $\mathrm{s}=$ stomata, $\mathrm{Sp}=$ spongy parenchyma, $\mathrm{Vb}=$ vascular bundle. Scale bars: Photograph $A=2 \mathrm{~cm}$, Scanning electron micrograph B-C, E = $100 \mu \mathrm{m}$, Optical D $=50 \mu \mathrm{m}$.

Fig. 4. Confocal micrographs of hydathode regions on a Brassica juncea leaf, showing nanoparticle penetration after incubation with water, nanocapsules (NC), or nanocapsules containing atrazine at $0.1 \mathrm{mg} \mathrm{mL}^{-1}$ (NC + ATZ). All the nanocapsules were labelled with 1,2-dipalmitoyl-sn-glycero-3phosphoethanolamine- $\mathrm{N}$-(Lissamine ${ }^{\mathrm{TM}}$ rhodamine $\mathrm{B}$ sulfonyl chloride) at $0.1 \%$ of miglyol mass in the oil phase. Arrowheads indicate stomata on the leaf surface and arrows indicate the green fluorescent signal of the dye. The first and third rows are focused on the leaf surface ( $A, C, E, G, I, K, M$, and $O)$, while the second and fourth rows are focused on the mesophyll level $(B, D, F, H, J, L, N$, and $P$ ). Scale bars = $20 \mu \mathrm{m}$.

Fig. 5. Scanning electron micrographs of the symptoms of atrazine toxicity (A-I) on the edge of a Brassica juncea leaf at 24 to $168 \mathrm{~h}$ after the plants were sprayed with water, empty nanocapsules (NC), nanocapsules containing atrazine 
with a 10 -fold dilution in water $(1 / 10 \mathrm{v} / \mathrm{v})(\mathrm{NC}+\mathrm{ATZ})$, or commercial atrazine (ATZ). Arrowheads indicate stomata or water pores on the leaf surface. Scale bars: $A=20 \mu \mathrm{m}, \mathrm{B}-\mathrm{I}=50 \mu \mathrm{m}$.

Fig. 6. Anatomical characterization of symptom evolution in Brassica juncea leaves under optical microscope. A-L. Transverse sections of the leaf blade at 24 to $168 \mathrm{~h}$ after the plants were sprayed with water, empty nanocapsules (NC), nanocapsules containing atrazine with a 10 -fold dilution in water $(1 / 10 \mathrm{v} / \mathrm{v})(\mathrm{NC}+$ $A T Z$ ), or commercial atrazine (ATZ). Arrows in $A, D$, and $H$ (inset) show chloroplasts, and arrows in B and $C$ show water pores. Epd = epidermis, $\mathrm{Ep}=$ epithem, $\mathrm{s}=$ stomata. Scale bars $=50 \mu \mathrm{m}$; inset in $\mathrm{H}=10 \mu \mathrm{m}$.

Fig. 7. A-V. Transmission electron micrographs showing atrazine symptoms at the ultrastructural level in leaves sprayed with water, empty nanocapsules (NC), nanocapsules containing atrazine with a 10 -fold dilution in water $(1 / 10 \mathrm{v} / \mathrm{v})(\mathrm{NC}+$ ATZ), or commercial atrazine (ATZ). Arrowheads indicate plastoglobuli, white arrows indicate thylakoid organization, and black arrows indicate nanoparticles. $R$ is the inset of the squared region in $\mathrm{Q} . \mathrm{c}=$ chloroplast, $\mathrm{cW}=$ cell wall, $\mathrm{m}=$ mitochondria, $v=$ vacuole, vs $=$ vesicle. Scale bars: $A-C, E, K, L, O, P, R$, and $S=$ $500 \mathrm{~nm} ; \mathrm{D}, \mathrm{H}$, and $\mathrm{J}=200 \mathrm{~nm} ; \mathrm{F}, \mathrm{T}$, and $\mathrm{U}=1 \mu \mathrm{m} ; \mathrm{G}, \mathrm{I}, \mathrm{M}, \mathrm{N}$, and $\mathrm{V}=2 \mu \mathrm{m} ; \mathrm{Q}=$ $5 \mu \mathrm{m}$. 


\section{Graphic for Table of Contents}

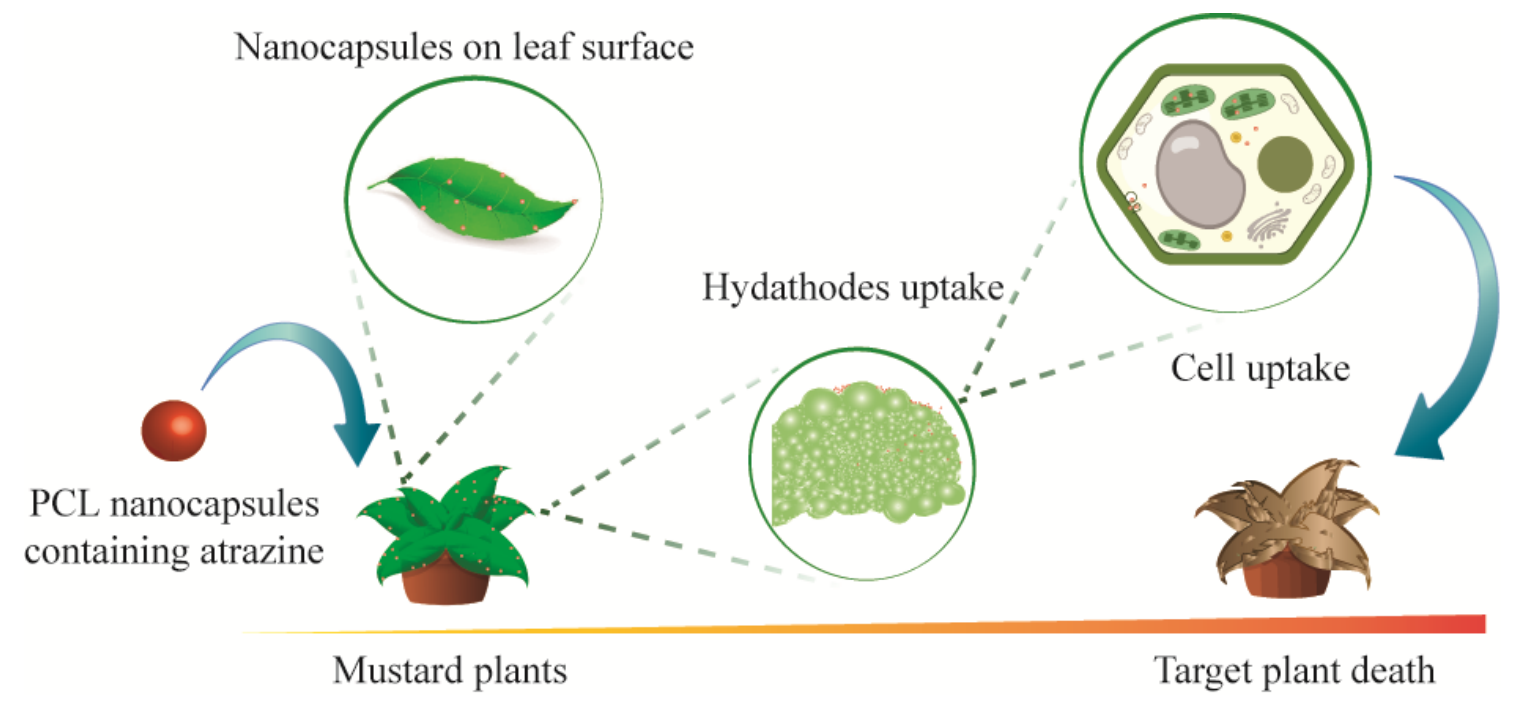

Figure 1

a)

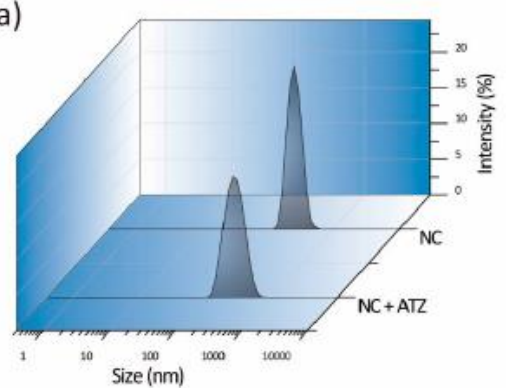

c)

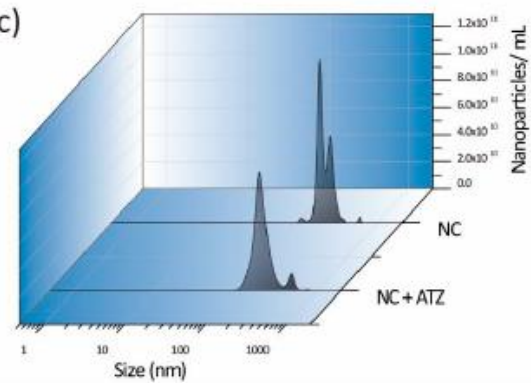

b)

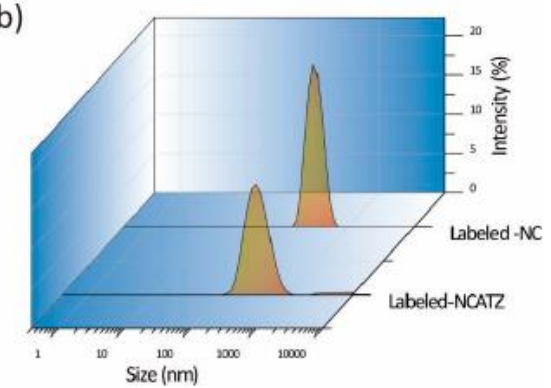

d)

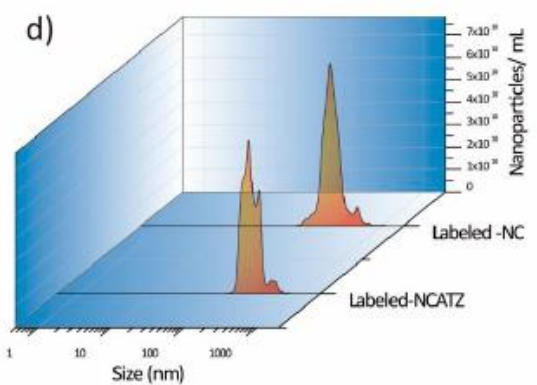


Figure 2

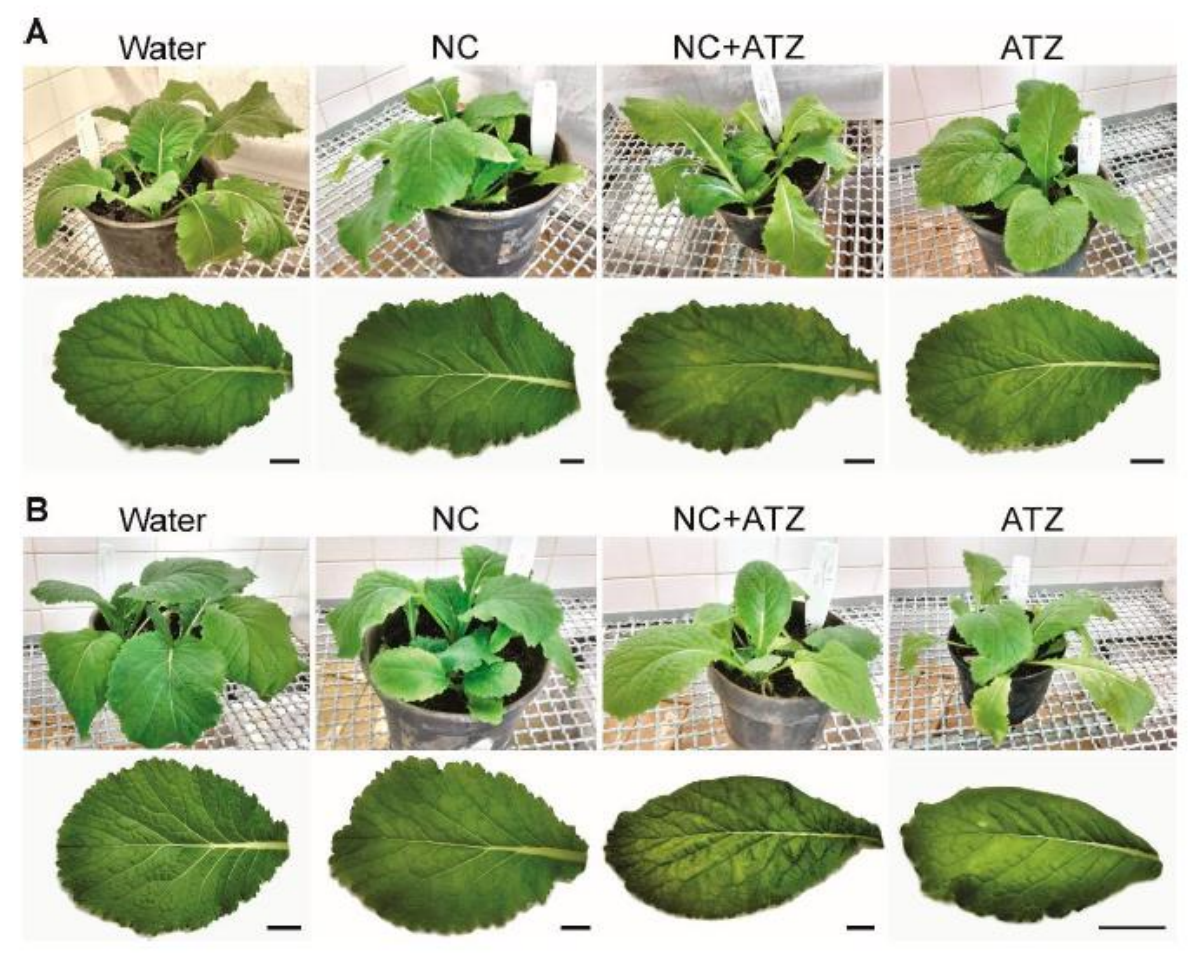

Figure 3

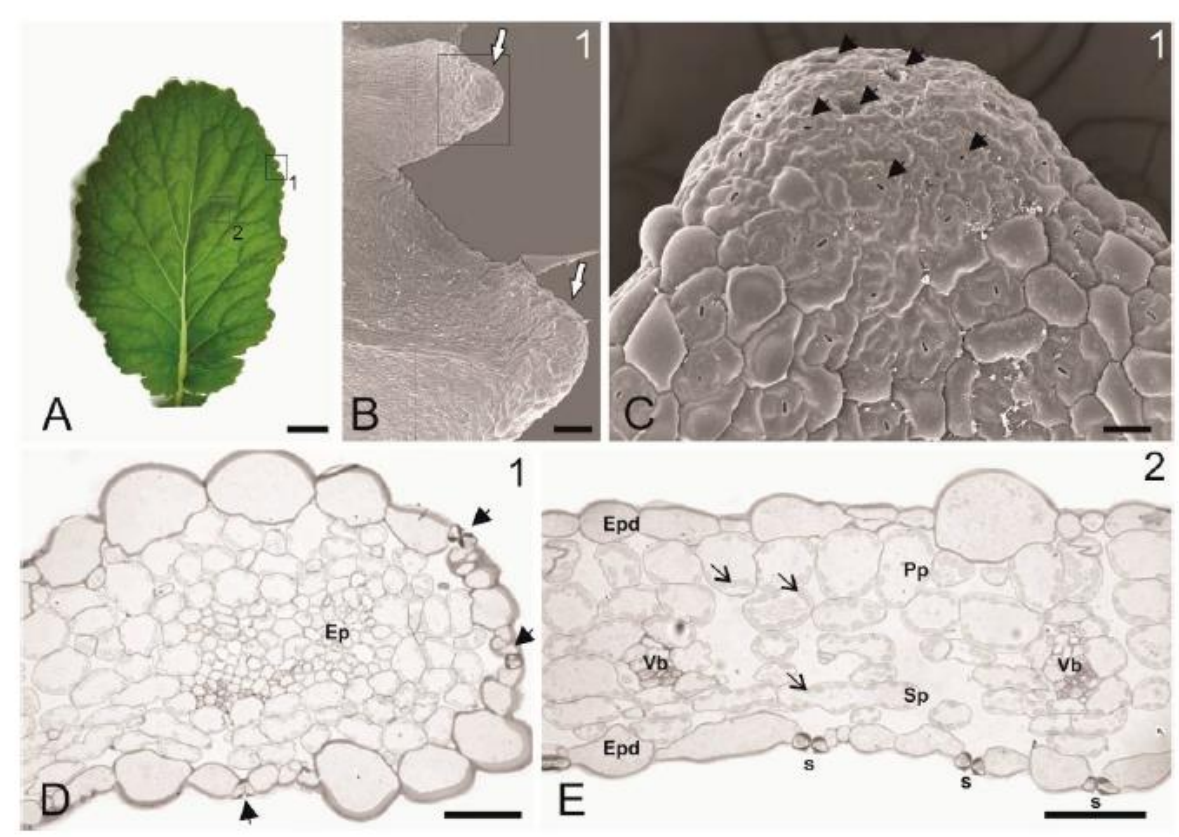


Figure 4

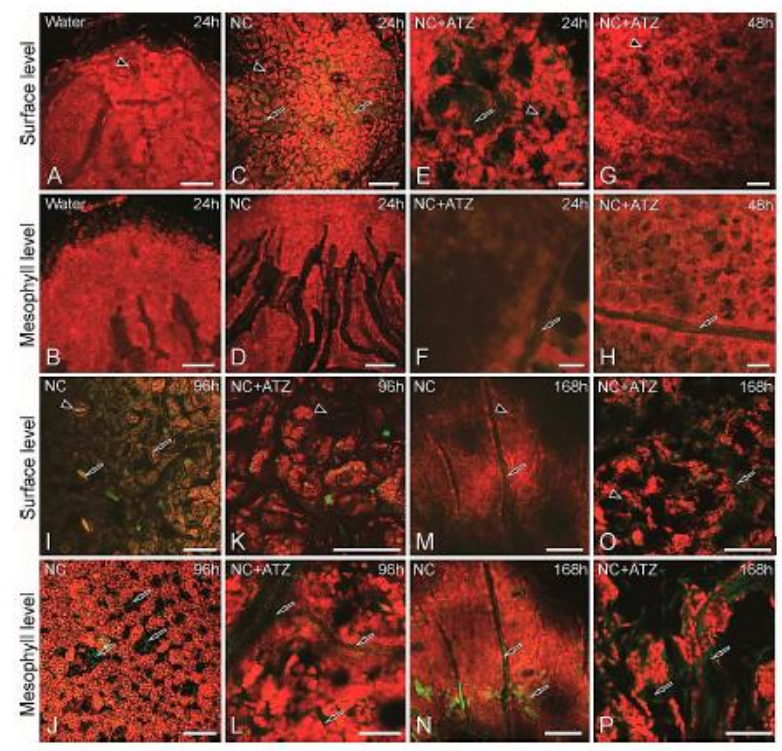

Figure 5

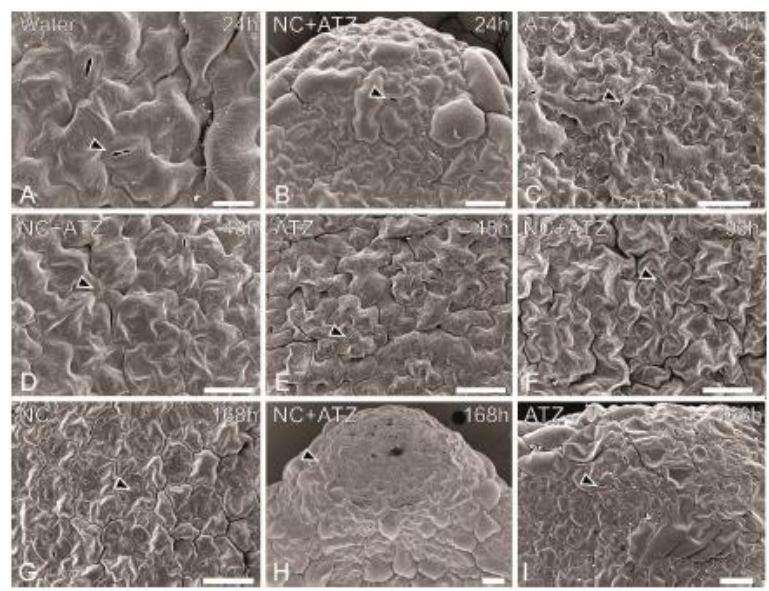


Figure 6

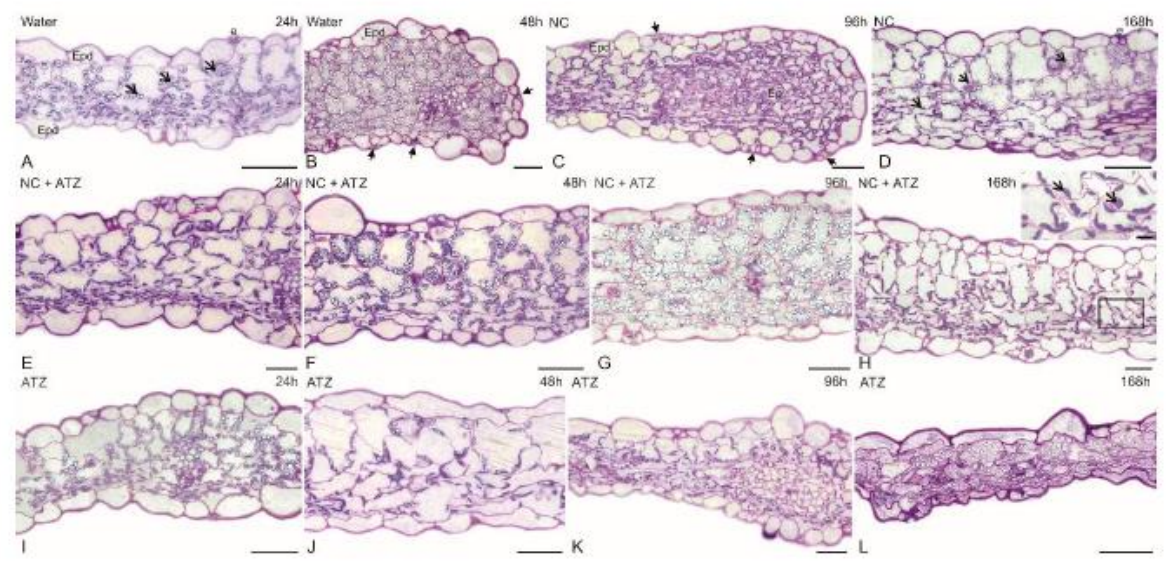

Figure 7

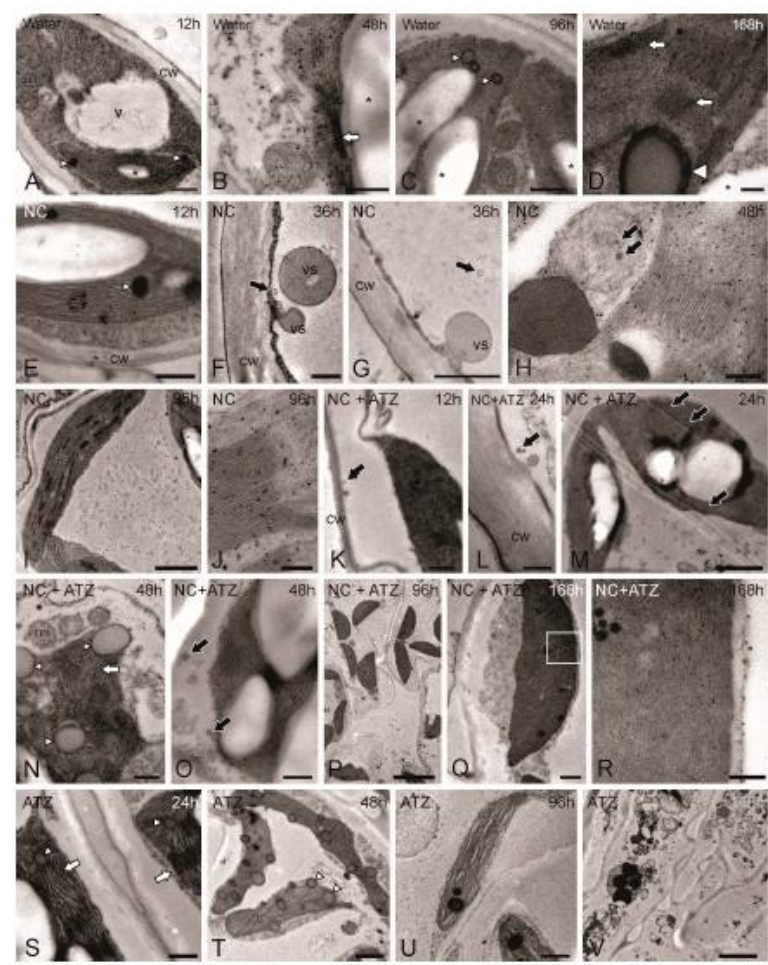

